

IBRACON Structures and Materials Journal

Revista IBRACON de Estruturas e Materiais

IBRACON

ISSN 1983-4195

ismj.org

ORIGINAL ARTICLE

\title{
A multi-physics modelling based on coupled diffusion equations to simulate the carbonation process
}

\section{Modelagem multi-física baseada em equações acopladas para a smilação da carbonatação}

\author{
Mateus Oliveira $^{\mathrm{a}}$ (D) \\ Miguel Azenha ${ }^{\mathrm{b}}$ \\ Paulo Lourenço ${ }^{\mathrm{b}}$ (D)
}

${ }^{a}$ Universidade Federal de Minas Gerais - UFMG, Departamento de Engenharia de Estruturas - DEES, Belo Horizonte, MG, Brasil

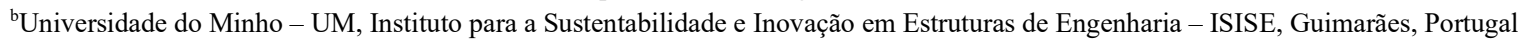

Received 25 June 2018

Accepted 12 February 2020

\begin{abstract}
Carbonation is widely recognized as a cause of significant pathologies in reinforced concrete structures and different modelling strategies are presented in literature the simulate the phenomenon evolution. In opposition to the deleterious effect in reinforced concrete, for historical mortar made with aerial lime, the carbonation is essential for the hardening process. For both materials, carbonation process presents similarities. This work presents the background/implementation of an algorithm for a multi-physics simulation of the main fields associated with the carbonation process. This modelling was previously validated in literature. A 1D algorithm is implemented, using the Finite Difference Method. Its feasibility is demonstrated through the simulation of results presented in the literature. A parametric study is also shown considering the main parameters involved, important observation regarding the influence of the parameters on the carbonation depth are detailed.
\end{abstract}

Keywords: multi-physics modelling, carbonation, concrete, aerial lime, finite difference method.

Resumo: A carbonatação é amplamente reconhecida como causa de patologias significativas em estruturas de concreto armado e diferentes estratégias de modelagem são apresentadas na literatura para simular a evolução do fenômeno. Ao contrário do efeito deletério do concreto armado, para argamassas históricas feitas com cal aérea, a carbonatação é essencial para o processo de endurecimento. Para ambos os materiais, o processo de carbonatação apresenta semelhanças. Este trabalho apresenta a implementação de um algoritmo para uma simulação multi-física dos principais campos associados ao processo de carbonatação. Essa modelagem foi validada anteriormente na literatura. Um algoritmo 1D é implementado, usando o Método das Diferenças Finitas. A viabilidade é demonstrada através da simulação dos resultados apresentados na literatura. Também é mostrado um estudo paramétrico, considerando os principais parâmetros envolvidos. São detalhadas observações importantes sobre a influência dos parâmetros na profundidade da carbonatação.

Palavras-chave: modelagem multi-física, carbonatação, concreto, cal aérea, método das diferenças finitas.

How to cite: M. Oliveira, M. Azenha, and P. Lourenço, "A multi-physics modelling based on coupled diffusion equations to simulate the carbonation process," Rev. IBRACON Estrut. Mater., vol. 13, no. 5, e13506, 2020, https://doi.org/10.1590/S1983-41952020000500006

\section{INTRODUCTION}

In reinforced concrete structures, over their service life, external deleterious substances may penetrate (e.g. carbon dioxide, chloride, sulfate) into concrete and find the rebars, altering the pore solution composition into aggressive conditions [1], [2]. Specifically considering the penetration of $\mathrm{CO}_{2}$, the main consequence is the occurrence of carbonation process. Carbonation is a major cause of concrete structures deterioration, therefore its evaluation should be carefully considered in the durability design of reinforced concrete structures [2]-[8]. 
In concrete or cement mortar, carbonation leads to a progressive decalcification of the hydrated cement paste. The pore interstitial solution constitutes a very alkaline environment ( $\mathrm{pH}$ close to 13.5), in which for reinforced concrete the rebars are passive [3]. When carbon dioxide $\left(\mathrm{CO}_{2}\right)$ from the atmosphere penetrates into the concrete pores, it dissolves in the interstitial solution and thereby modifies the chemical balances between the solution and the hydrates. This leads to the precipitation of calcium carbonates $\left(\mathrm{CaCO}_{3}\right)$ in ordinary Portland cementitious materials [9]-[11], as well as the densification of the microstructure and the decrease of the $\mathrm{pH}$ of interstitial solution [3]. Therefore, the reinforcement is not protected anymore, in this sense, carbonation leads to the degradation of the reinforced concrete structures. The reactions of cement-based materials occur in natural environment at a quite slow rate due to the reduced $\mathrm{CO}_{2}$ concentration in the atmosphere [1], [2]. In opposition to the deleterious effects, recently, research interests focusing on the beneficial aspects of carbonation of cement-based materials have been observed [12]. In literature, there are two major beneficial of carbonation [12], [13]: (i) rapid strength gain of the cementitious matrix when subjected to curing in the presence of $\mathrm{CO}_{2}$ [12], [13], and (ii) sequestration of $\mathrm{CO}_{2}$ in concrete [14], [15].

Concrete is the second largest commodity (in terms of volume) consumed annually (after water) [12], [13]. Therefore, concrete and other cement-based materials may present the potential to be one of the largest global $\mathrm{CO}_{2}$ sequestration [14]. As mentioned, the carbonation phenomenon in cementitious materials is a very relevant subject, and it has been studied by different authors [2]-[8].

However, the development of Portland cement is relatively recent, in the 19th century [6], consequently several other materials were previously used. One example of these materials is the aerial lime (non-hydraulic lime). The application of aerial lime in construction was recurrent until the $19^{\text {th }}$ century [16], [17]. Aerial lime is frequently found in historical structures in several parts around the world. This material is basically composed of $\mathrm{CaO}$ and, in some cases, it may present a considerable amount of $\mathrm{MgO}$ as well.

In recent times, the interest in lime-based materials is increasing due to study, restoration and preservation of historic buildings [10], [11], as they are compatible with traditional building materials [6], [18], since Portland cement shows low chemical and physical affinity [6], [19], [20]. There are few studies about carbonation in aerial lime-based materials, when comparing with concrete, especially regarding the numerical aspect [10], [21], [22]. In terms of experiments, some references are present in literature [10], [23]-[25].

After this introduction, it should be highlighted that for both material (concrete and aerial lime-based mortars), several factor affect the process [26], such as: ambient relative humidity, concentration of carbon dioxide, surface protection, concrete permeability, water-binder ratio, time of exposure, and other [27], [28].

In summary, carbonation is a major cause of concrete structures deterioration, therefore its evaluation should be carefully considered in the durability design of reinforced concrete structures and for aerial lime based-materials, it is essential for the development of mechanical properties. Due to the complexity involved on the phenomenon, the use of multi-physics formulations are suggested by different authors [10], [21], [22].

The present paper presents a critical literature review about multi-physics models, considering scientific aspects. A recognized formulation is chosen and implemented using Finite Difference Method. In sequence, adopting this software, several studies are presented analyzing the evolution of carbonation process. The influence of different parameters on the carbonation depth is evaluated, in association with the study of the effect of the size/dimensions of the specimen, see Figure 1.

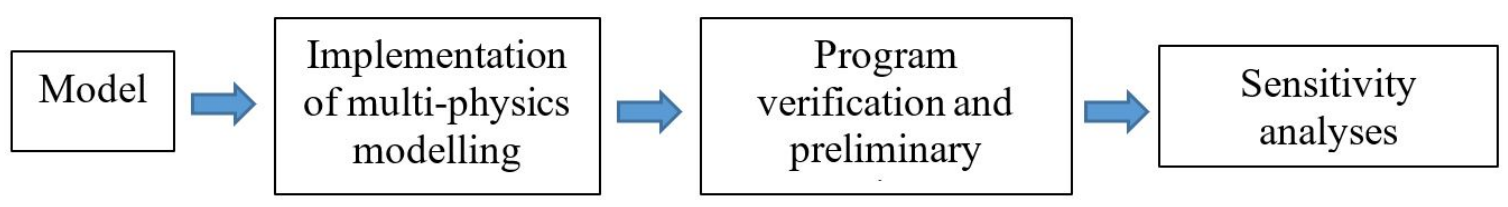

Figure 1. Work organization

\section{Multi-physics models for simulation of carbonation process}

In this section, some general information about different multi-physics models are presented. Different strategies were chosen with a large number of parameters involved. A model based on thermo-hygro physics is presented by Ishida and $\mathrm{Li}$ [29], Ishida and Maekawa [30] and Ishida et al. [31]. The model coupled with moisture equilibrium/transport, temperature dependent parameters were also assumed [29]. 
The modelling recommended by Bary and Sellier [2] is based on macroscopic mass balance equations for water, the carbon dioxide contained in gaseous phase and the calcium present in the pore solution [2]. These equations rule the diffusion and permeation processes of the three variables: saturation degree, carbon dioxide partial pressure and calcium concentration in pore solution [2].

Coupling between carbonation and chloride diffusion is explored in the context of both homogeneous and heterogeneous concrete models [32], this model considers the coupling of heat, relative pore humidity, chloride, and carbonation fields [32].

\section{Models based on simple diffusion equations}

The multi-physics models from literature summarized in this section are based on the $\mathrm{CO}_{2}$ modeling using a simple diffusion equation.

The study done by Burkan Isgor and Razaqpur [4] presents a general diffusion model implemented in Finite Element Method) for thermo-carbo-hygro simulations, the modelling strategy is decoupled with mechanical aspects. In another research, Steffens et al. [33] adopted a diffusion model to study the carbonation. The model proposed by the authors [33] combines results of extensive studies by Bunte and Rostasy [34] on diffusion of $\mathrm{CO}_{2}$ in different types of concrete and the modeling of the reaction kinetics of carbonation by Saetta et al. [35] with a coupled temperature and moisture modelling strategy, it considers that the $\mathrm{CO}_{2}$ penetrates into the concrete mainly gaseous by diffusion through air-filled pores [10], [33]. Additionally, Meier et al. [36] presents a similar mathematical, in continuity, Peter et al. [37] include the hydration reactions in strategy presented by Meier et al. [36].

The mathematical modelling of carbonation process for concrete and mortars is complex [10]. The first model adopted to simulate the aerial lime mortar carbonation was shown by Ferretti and Bažant [21], for that reason, and considering the complexity involved and the requirements of information about the material, the strategy presented by Ferretti and Bažant [21] has been chosen for this work (description may be see next section). This modelling strategy has been chosen because it is the only modelling presented in literature to simulate the carbonation process in aerial lime mortar.

\section{- Model of Ferretti and Bažant [21]}

This section presents the mail information about the modelling strategy presented by Ferretti and Bažant [21] This model is a multi-physics coupled model involving four fields, humidity, heat, pollutant flow $\left(\mathrm{CO}_{2}\right)$ and reaction [10]. The numerical model for deterioration was developed, considering the characterization of the concrete and the environmental conditions [10]. The present mathematical model is based on studies conducted by Saetta [38], Saetta et al. [35] and Saetta et al. [39], Saetta and Vitaliani [9]. The modelling presented herein was also experimentally validate in previous studies conducted by Saetta and Vitaliani [9]. The equations used to model the phenomena are presented below.

The humidity field [21], [28], [39], [40] is governed by:

$$
\frac{\partial h}{\partial t}=\nabla\left(C_{w} \nabla h\right)+\alpha_{2} \frac{\partial R}{\partial t}
$$

where: $\mathrm{h}$ reads as the humidity (\%), $\alpha_{2}$ means the parameter related to the water generation during the carbonation process (more details are presented in sequence), $C_{w}$ is the diffusion of water $\left(\mathrm{mm}^{2} /\right.$ day) and $\mathrm{R}$ is the degree of chemical reaction (\%) [9].

The coefficient $\alpha_{2}$ is related to the maximum content of calcium carbonate $\left[\mathrm{CaCO}_{3}\right]_{\max }=P_{\max }$ (the term $P$ represents the formation of $\mathrm{CaCO}_{3}$ ), which depends mostly on the material composition. The angular coefficient of the sorptiondesorption isotherm $k$, dependent fundamentally on temperature [9]:

$$
\alpha_{2}=\frac{P M\left(\mathrm{H}_{2} \mathrm{O}\right)}{P M\left(\mathrm{CaCO}_{3}\right)} k P_{\max }=0.18 k P_{\max }
$$

where: $P M$ represents the molecular weight of the molecule. 
This equation derives from the kinetic of the carbonation reaction [9], [10]. For each $\mathrm{CaCO}_{3}$ molecule produced by the reaction, a molecule of water is also created, consequently, considering the molecular mass [9], [10]:

$M_{\mathrm{H}_{2} \mathrm{O}}=M_{\mathrm{CaCO}_{3}} \frac{\mathrm{PM}\left(\mathrm{H}_{2} \mathrm{O}\right)}{\mathrm{PM}\left(\mathrm{CaCO}_{3}\right)}$

where: $M$ denotes the molecular mass of the molecule specified.

Accordingly, in terms of mass per unit volume, Equation 3 may be redefined as:

$\frac{M_{\mathrm{H}_{2} \mathrm{O}}}{V_{c l s}}=\frac{M_{\mathrm{CaCO}_{3}}}{V_{c l s}} \frac{P M\left(\mathrm{H}_{2} \mathrm{O}\right)}{P M\left(\mathrm{CaCO}_{3}\right)}$

where: $V_{c l s}$ is the considered volume of element, consequently [9]:

$$
d w=d P^{*} \frac{P M\left(\mathrm{H}_{2} \mathrm{O}\right)}{P M\left(\mathrm{CaCO}_{3}\right)}
$$

where: $d w$ represents the water content variation per unit volume and unit time, while $d P^{*}$ is the variation of the calcium carbonate concentration (such variables are both expressed in $\mathrm{kg} / \mathrm{m}^{3}$ ) [9].

By using the well-known expression of the sorption-desorption isotherms, i.e., $k h d w=d h$ [10], [41], and expressing the calcium carbonate content as $d R=d P^{*} / P_{\max }$, it is possible to write [9]:

$\frac{\partial h}{\partial t}=\frac{P M\left(\mathrm{H}_{2} \mathrm{O}\right)}{P M\left(\mathrm{CaCO}_{3}\right)} k P_{\max } \frac{\partial R}{\partial t}$

which compared with Equation 6, with $\mathrm{PM}\left(\mathrm{H}_{2} \mathrm{O}\right)=18.015$ and $\mathrm{PM}\left(\mathrm{CaCO}_{3}\right)=100.088$ [10], [42], gives Equation 2. Assuming, for illustration, that $P_{\max }=0.0096 \mathrm{~kg} / \mathrm{m}^{3}$ and $k h=1 \mathrm{~m}^{3} / \mathrm{kg}$, then $\alpha_{2}=0.0017$. The analytical determination of the coefficient $\alpha_{2}$ proves somewhat uncertain because it is difficult to unequivocally assign the coefficients $\mathrm{k}_{\mathrm{h}}$ and $P_{\max }$. The carbon dioxide diffusion field is governed by:

$$
\frac{\partial c}{\partial t}=\nabla\left(D_{c} \nabla c\right)-\alpha_{3} \frac{\partial R}{\partial t}
$$

where: $\alpha_{3}$ is the parameter related to gas consumption during the carbonation process, Dc represents the diffusion of the gas $\left(\mathrm{CO}_{2}\right.$ for instance) and $\mathrm{c}$ is the gas concentration (\%).

Equation 7 is based on the second Fick's law. Parameter $\alpha_{3}$ is influenced by the carbonation, and based on a considerations on the chemistry of this reaction. The reaction field is governed by:

$$
\frac{\partial R}{\partial t}=\alpha_{4} \times F_{l}^{R}(h) \times F_{2}^{R}(c) \times F_{3}^{R}(R) \times F_{4}^{R}(T)
$$

where: $\mathrm{T}$ means the temperature $(\mathrm{K})$.

The carbonation (the degree of reaction) is defined as:

$$
R=\frac{\left[\mathrm{CaCO}_{3}\right]}{\left[\mathrm{CaCO}_{3}\right]_{\max }}
$$


where: $\left[\mathrm{CaCO}_{3}\right]_{\max }$ is the maximum mass concentration of calcium carbonate $\left(\mathrm{kg} / \mathrm{m}^{3}\right)$, and $\left[\mathrm{CaCO}_{3}\right]$ is the actual mass concentration of $\mathrm{CaCO}_{3}\left(\mathrm{~kg} / \mathrm{m}^{3}\right)$ [10], [28], [40].

The functions $F_{l}$ to $F_{4}$, are defined in sequence, further information may be seen in literature [10], [21], [28], [39], [40].

$C_{w}=C_{w, r i f} \times f_{1}^{*}(h) \times f_{2}(T) \times f_{3}\left(t_{e}\right) \times f_{4}(R)$

$D c=D c_{r i f} \times f_{l}(h) \times f_{2}(T) \times f_{3}\left(t_{e}\right) \times f_{4}(R)$

where: $C_{w, \text { rif }}$ and $D_{c r i f}$ are the diffusivities in standard conditions for water and $\mathrm{CO}_{2}$ respectively $\left(\mathrm{mm}^{2} /\right.$ day).

The function $f_{1}^{*}(h)$ is defined as:

$f_{l}^{*}(h)=\alpha+\frac{1-\alpha}{1+\left(\frac{1-h}{1-h_{c}}\right)^{n}}$

where: $\alpha, h_{c}$ and $\mathrm{n}$ were already defined in Equation $\left(\alpha=0.05, h_{c}=0.75\right.$ and $\left.n=6\right)$.

For gas diffusion phenomena (for instance $\mathrm{CO}_{2}$ ), the following expressions are given:

$$
f_{l}(h)=(1-h)^{2.5}
$$

$f_{2}(T)=\exp \left[\frac{E_{a}}{R}\left(\frac{1}{T_{0}}-\frac{1}{T}\right)\right]$

where: $T_{0}$ means the reference temperature $(296 \mathrm{~K}), E a$ is defined as the activation energy $(\mathrm{kJ} / \mathrm{mol}), R$ reads the universal gas constant $(\mathrm{J} / \mathrm{mol} \times \mathrm{K})$, and $\mathrm{T}$ is temperature.

Function $f_{3}\left(t_{e}\right)$ is related to the concept of equivalent age, and it is defined as:

$f_{3}\left(t_{e}\right)=\chi+(1-\chi)\left(\frac{28}{t_{e}}\right)^{0.5}$

where: $t_{e}$ is the equivalent age (days).

The diffusion process is reduced with the decreasing of the porosity, to simulate this phenomenon a function $f_{4}(R)$ may be defined as [43]:

$f_{4}(R)=1-\zeta R$

where: parameter $\zeta$ varies between 0 and 1 , and measures the slowing of diffusion phenomenon due to reduction of the porosity [38]-[40]. Ferretti and Bažant [21] adopted $\zeta=0.3$, meaning that a reduction of $30 \%$ for the diffusivity value occurs with the total reaction, further information and other values for this value can be seen in literature [10], [28], [40].

Function $F_{4}{ }^{R}$ describes the influence of temperature on the progress of the chemical reaction, it may be expressed as [21], [33]:

$F_{4}{ }^{R}(T)=A \times e^{-\frac{E_{a}}{R T}}$

where: $A$ is the impact number [33] and $E_{a}$ means the activation energy $(\mathrm{kJ} / \mathrm{mol})$. 
After the description of the modelling approach, some considerations should be addressed. Considering these facts, in literature the number of works that use the multi-physics modelling strategies are raising, however more development are necessary [10]. In general terms, the multi-physics modelling strategy may be still considered a complex simulation, since it required advanced computational tools and a deep understand of the material behavior and phenomena coupling and the process of obtaining parameters is still a challenge.

Specifically considering the modelling strategy implemented in the present work [21], it may be considered a powerful tool, however some limitations are implicates: e.g. it does not consider others couplings with aggressive agents (e.g. chlorides, sulfates) and the movement of fluids are based are based on simple processes. A general review about the modelling strategies and the complexities involved may be seen in literature [10].

\section{RESULTS AND DISCUSSIONS}

\section{Implementation of multi-physics modelling: A brief discussion}

This section describes the strategy of implementation used to simulate the carbonation process. The coupled model is based on the work of Ferretti and Bažant [21], and it is implemented using the Finite Difference Method (FDM) [44].

The decoupled humidity field for 1D using FDM is previously presented in Oliveira et al. [45]. For carbon dioxide field, the mathematical implementation is similar, thus for the sack of brevity, the implementation of both fields are herein omitted, further details may be seen in literature [45].

All simulations of present work assume constant temperature, for the sake of brevity, no further details will be herein. The model has been implemented in 1D, axisymmetric and 2D conditions, further information may be found in and Oliveira [10]. For brevity and due to the similarity with the 1D implementation, the 2D and axisymmetric implementations are not presented herein, more details can be seen in Oliveira [10]. The chosen notation for reaction field $R$ is the same adopted in Oliveira et al. [45], where " $i$ " represents the node, and " $n$ " reads as the time step [10]. Adopting small values of time step and of length between the nodes in FDM grid, it may be assumed $d x=\Delta x$ and $d t=\Delta t$.

Equation 21 represents the equation used to simulate the reaction field. Replacing in Equation 21 the definition of $F_{2}(c)$, provides:

$$
\frac{\partial R}{\partial t}=\alpha_{1} \times F_{1}^{R}(h) \times \frac{c}{c_{\max }} \times F_{3}(R) \times F_{4}(T)
$$

The evolution of reaction field over time in Finite Difference Method may be expressed as:

$$
\frac{\partial R}{\partial t}=\frac{R_{n+1}^{i}-R_{n}^{i}}{\Delta t}
$$

Substituting Equation 22 in Equation 21, it may be obtained:

$$
R_{n+1}^{i}=R_{n}^{i}+\Delta t \times\left(\alpha_{1} \times F_{4}^{R}(T) \times F_{l}^{R}(h) \times \frac{c_{n+1}^{i}}{c_{\max }} \times\left(1-R_{n+1}^{i}\right)\right.
$$

This equation may be reorganized as:

$$
\left(1+\Delta t \times\left(\alpha_{1} \times F_{4}(T) \times F_{I}(h) \times \frac{c_{n+1}^{i}}{c_{\max }}\right)\right) \times R_{n+1}^{i}=R_{n}^{i}+\Delta t\left(\alpha_{1} F_{4}(T) \times F_{I}(h) \times \frac{c_{n+1}^{i}}{c_{\max }}\right)
$$

Rearranging the equation, the expression for inner nodes, it reads: 
$\left(1+\Delta t \times\left(\alpha_{1} \times F_{4}{ }^{R}(T) \times F_{1}^{R}(h) \times \frac{c_{n+1}^{i}}{c_{\max }}\right)\right) \times R_{n+1}^{i}-\Delta t\left(\alpha_{1} F_{4}^{R}(T) \times F_{l}^{R}(h) \times \frac{c_{n+1}^{i}}{c_{\max }}\right)=R_{n}^{i}$

The definition of $F_{4}^{R}(T)$ will not be the used herein, because the temperature is assumed constant.

For coupled humidity field, considering the development done in Oliveira [10] (decoupled humidity field) and the humidity coupled equation with reaction field $\left(\alpha_{2}(\partial R / \partial t)\right)$, the final equation for humidity field for inner nodes (except in the boundary and symmetry) is given by:

$$
h_{n+1}^{i} \times\left(\left(1+2 \times \Delta t \times \frac{C_{w, n+1}^{i}}{(\Delta x)^{2}}\right)-\Delta t \times\left(C_{w, n+1}^{i} \times \frac{h_{n+1}^{i+1}+h_{n+1}^{i-1}}{(\Delta x)^{2}}\right)\right)-\alpha_{2} \times R_{n+1}^{i}=h_{n}^{i}-\alpha_{2} \times R_{n}^{i}
$$

As already cited, the effective humidity and $\mathrm{CO}_{2}$ diffusivity depends on the other fields $(R, h$ and $c)$ and $C_{w}$, from Equation 26 is needed to solve numerically the problem. Herein, details about this development is omitted, for the sake of brevity. More details may be seen in literature [10].

Considering the equation for carbon dioxide, with the coupling term related to reaction field (term $\alpha_{3}(\partial R / \partial t)$ ), the following expression is obtained in case of the inner nodes (except in the boundary and symmetry):

$$
c_{n+1}^{i} \times\left(\left(1+2 \times \Delta t \times \frac{D c_{n+1}^{i}}{(\Delta x)^{2}}\right)-\Delta t \times\left(D c_{n+1}^{i} \times\left(\frac{c_{n+1}^{i-1}+c_{n+1}^{i+1}}{(\Delta x)^{2}}\right)\right)\right)+\alpha_{3} R_{n+1}^{i}=c_{n}^{i}+\alpha_{3} R_{n}^{i}
$$

For the boundary and symmetric nodes, Equations 26 and 27 may be adapted as also done for the decoupled humidity field in appling Neumman boundary condition, or an imposed/fixed value adopting the Dirichlet formulation [44].

The terms of equation expressed in time " $n+1$ " are in the left side, while terms in time " $n$ " are shown in right side. In sequence, general considerations regarding the numerical simulation of humidity field for 2D condition in FDM are following discussed. The current implementation considers the field equation, which may be revised adopting the application of the chain rule [46]:

$$
\frac{\Delta h}{\Delta t}=\nabla D_{h} \nabla h+D_{h} \nabla^{2} h+\alpha_{2} \frac{\partial R}{\partial t}
$$

After this discussion, Figure 2 schematic represents the solution of the coupled system of equations. The symbol $\left({ }^{\wedge}\right)$ denotes a matrix or a vector, while the superscript/subscript denotes the iteration/step. $\hat{H}_{n}, \hat{R_{n}}$ and $\hat{c_{n}}$ represent respectively the humidity, reaction and carbon dioxide vectors for each field in time " $n$ ". $R H c$ is a vector with all the fields (reaction, humidity and carbon dioxide). Generically the matrix in right side matrix is denominated $\hat{F}_{n}^{i}$, the vector presenting all the fields expressed in time " $n+1$ ” as $\hat{R H c^{i}}{ }_{n+1}$ and the residual vector of iterations is expressed as $\hat{\psi}$.

It should be highlighted that, for tolerance, three different values (toler humidity, toler $_{\text {reaction }}$ and toler carbon_dioxide $_{\text {) were }}$ chosen, since the order of magnitude of each filed was dissimilar, further information may be seen in literature [10]. With the purpose of validate the implemented modelling, the 1D results presented in the work of Ferretti and Bažant [21] were numerically simulated. The authors [21] studied the failure of Pavia Tower in Italy [10], [47]-[49]. In order to validate the independence of the analysis from time and spacing discretization, diverse values of time steps and nodal distance were tested. The results presented small discrepancies further details may be seen in Oliveira [10]. 


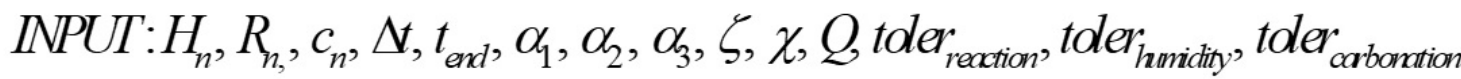
OUTPUT:H ${ }_{n+1} ; c_{n+1}$ and $R_{n+1}$

updated time: $t_{n+1}=t_{n}+\Delta t$ is $\rightarrow t_{n+1}>t_{\text {end }}$ ? No: Go to step (ii) / Yes: go to step (x)

(ii) Initialize iteration counter $i=0 \rightarrow \operatorname{set} \rightarrow t_{n+1}^{i=0}=0$

For all the node: $R^{\text {trial }}=R_{n}, H^{\text {trial }}=H_{n}$ and $c^{\text {trial }}=c_{n} \rightarrow$ Build the vector $R H c_{n+1}^{i}, \Delta R H c_{n}^{0}=0$

(iii) Set $R H c_{n+1}^{i}=R H c_{n}^{i}+\Delta R H c_{n}^{i}$

(iv) Compute matrix: $\hat{F}_{n}^{i}$ with basis on previous step / Compute: $\hat{K}_{n+1}^{i}$

(v) Compute residual vector: $\hat{\psi}_{n+1}=\hat{F}_{n}^{i}-\hat{K}_{n+1}^{i} \times R \hat{H} c_{n+1}^{i}$

Assign: $\hat{\psi}_{n+1}^{i} n+1$ (reaction),$\hat{\psi}_{n+1}^{i} n+1$ (humidity),$\hat{\psi}_{n+1} n+1($ carbon_dioxide $)$

(vi) Check convergence:

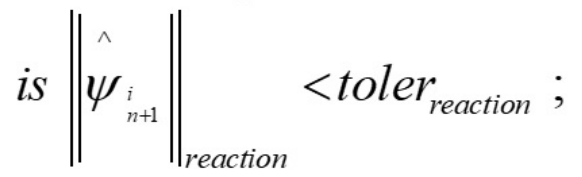
and<smiles>CC(=O)CC1CC1C1CC1</smiles>

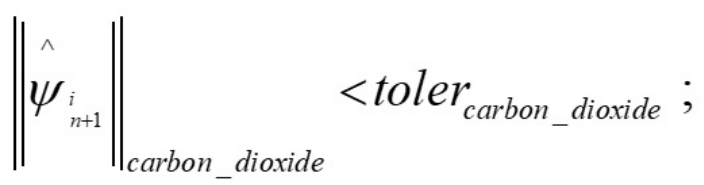

and

No: Go to (vii) / Yes: Go to (ix)

(vii)

$$
\text { compute } \rightarrow \Delta R \hat{H} c_{n+1}^{i+1}=\Delta R \hat{H}^{i}{ }_{n+1}+\left[\hat{K}_{n+1}^{i}\right]^{-1} \hat{\psi}_{n+1}^{i}
$$

(vii) Update the iteration counter $i=i+1$. Go to (iii)

(ix) Update the iteration counter $n=n+1$. Go to (i)

(x) End 


\section{RESULTS: SENSITIVITY ANALYSES}

Several sensitivity analyses were done during the study, changing the input model parameters, more information can be seen in Oliveira [10]. For these, a 1D wall with two meters $(2 \mathrm{~m})$ length, in contact with the environment in the two boundaries was simulated. The obtained results are presents for one meter, because of the symmetry condition (at 1 meter). For the numerical simulations, the distance "zero" (the first node) represented the node in contact with the environment, and the node located at distance one meter $(1 \mathrm{~m})$ was the symmetric one, more information can be seen in Oliveira [10]. In order to illustrate the obtained results, the analyses for 50 years are shown. The parametric analyses regarding the $\mathrm{CO}_{2}$ initial diffusivity $\left(D_{c, r i j}\right)$ was studied and wholly parameters were based on the Ferretti and Bažant [21].

The parametric results for $\mathrm{CO}_{2}$ initial diffusivity are shown, since the large influence of this parameter on the final carbonation results. A range from one hundred times higher and smaller the value adopted by Ferretti and Bažant [21] was considered $\left(D_{c, r i f}=2400 \mathrm{~mm}_{2} /\right.$ day, this is cited as the next figures as "typical value"). Time and nodal discretization were adopted with constant values $(\Delta t=1$ day and $\Delta x=1.25 \mathrm{~cm})$. For the initial conditions, the considerations adopted above were maintained. Figure 3 shows the results for $\mathrm{CO}_{2}$ concentration and Figure 4 shows the results for the reaction field.

The carbonation profile was expressively affected by the initial diffusivity of $\mathrm{CO}_{2}$. This effect was expected. After 50 years, the wall presented distinct reaction profiles, according to the used parameter. For instance, the carbonation front was located on the first $5 \mathrm{~cm}$ of the wall, if the diffusivity $D_{c, \text { rif }}=24 \mathrm{~mm}^{2} /$ day (the smallest value); while the wall presented around $80 \mathrm{~cm}$ with $R=1$, for $D_{c, \text { rif }}=240000 \mathrm{~mm}^{2} /$ day. These cases with extreme values illustrated, the importance of the parameters' selection for the numerical model, further information can be seen in Oliveira [10].

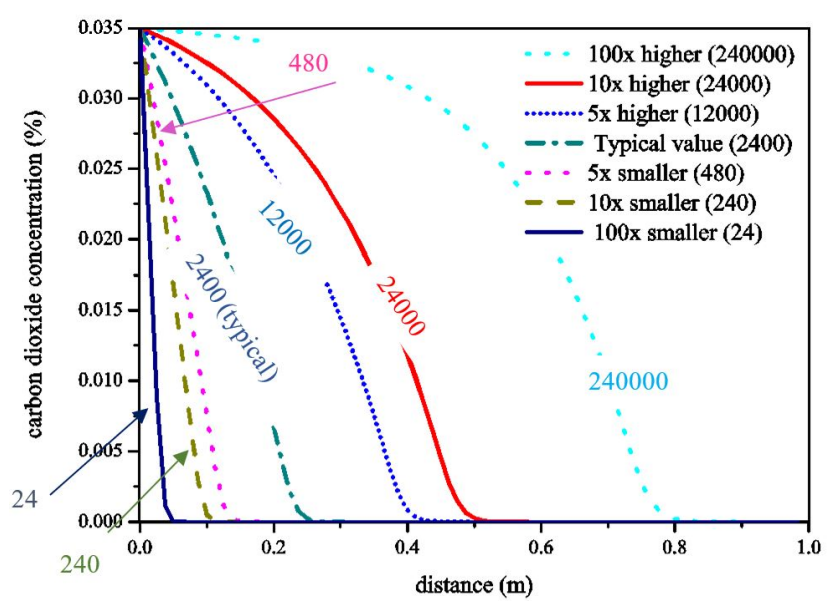

Figure 3. Parametric analyses, results for carbon dioxide field - Initial $\mathrm{CO}_{2}$ diffusivity (values in $\mathrm{mm}^{2} /$ day) - 50 years - Given the symmetry, in this figure only half of the profile is presented

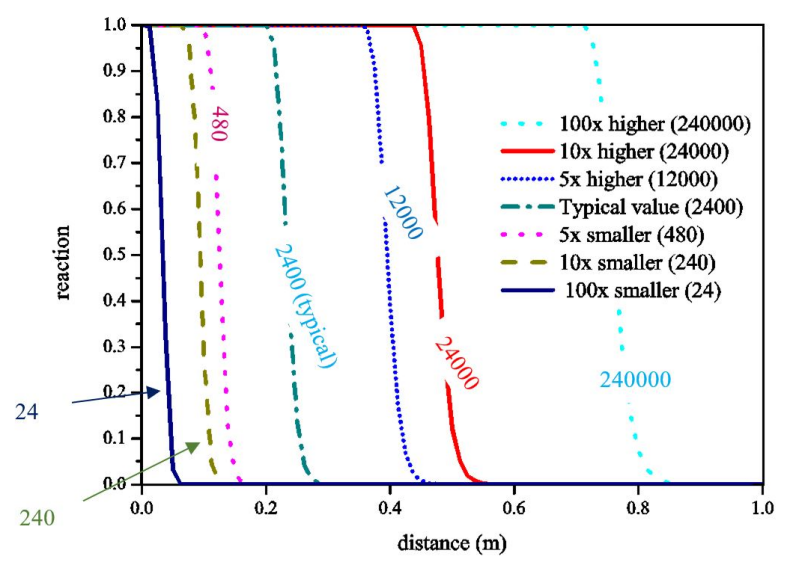

Figure 4. Parametric analyses, results for reaction field - Initial $\mathrm{CO}_{2}$ diffusivity (values in $\mathrm{mm}^{2} /$ day) - 50 years - Given the symmetry, in this figure only half of the profile is presented 
Results for the humidity field are shown in Figure 5. The influence of $D_{c, r i f}$ was on the carbon dioxide and reaction fields. On the contrary, the parameter did not affect significantly the results in terms of humidity field. The tendency for 50 years was also observed for different ages, further information can be seen in Oliveira [10].

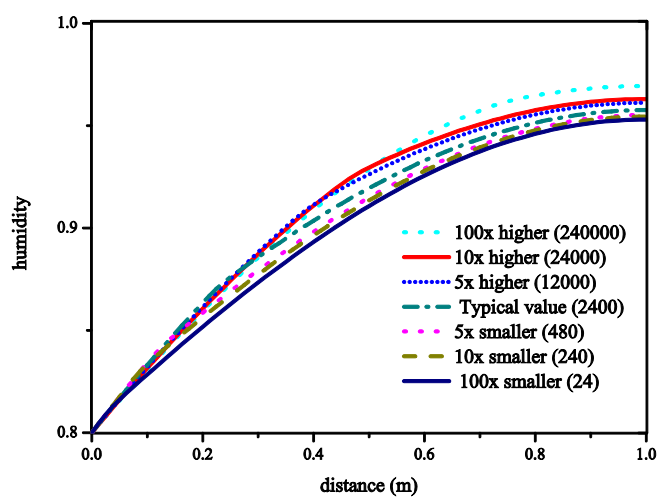

Figure 5. Parametric analyses, results for humidity field - Initial $\mathrm{CO}_{2}$ diffusivity (values in $\mathrm{mm}^{2} /$ day) - 50 years - Given the symmetry, in this figure only half of the profile is presented

The same range of values for the initial carbon dioxide diffusivity $\left(D_{c, r i f}\right)$ was adopted, and in order to illustrate the behavior for longer ages, further information can be seen in Oliveira [10]. A node located at $40 \mathrm{~cm}$ from the boundary in contact with the environment was selected. The results for reaction field, for this node, in analyses over 500 years ( 182500 days) are shown in Figure 6. For horizontal axis, the upper scale in Figure 6 indicated in "years" and the bottom is indicated in "days" to facilitate the understanding, further information can be seen in Oliveira [10].

The results presented in Figure 6, indicated the significant dependence of the reaction profile for this depth, according with the value for the initial the $\mathrm{CO}_{2}$ diffusivity. The same dependence happened for the others depths, further information can be seen in Oliveira [10].

Unambiguously for the results presented in Figure 6, when the highest value for the carbon dioxide diffusivity was adopted, $D_{c, r i f}=240000 \mathrm{~mm}^{2} /$ day, or equivalently one hundred time higher than the value cited by Ferretti and Bažant [21], after around 30 years ( 1095 days), the reaction was completely $(R=1)$. On the other hand, for the $D_{c, r i f}=2400 \mathrm{~mm}^{2} /$ day or equivalently the value cited by Ferretti and Bažant [21], the reaction reached values close to one $(R \approx 1)$ after around 400 years ( $\sim 146000$ days), further discussion about this issue can be seen in Oliveira [10].



Figure 6. Parametric analyses, results for reaction field over time - Initial $\mathrm{CO}_{2}$ diffusivity (values in $\mathrm{mm}^{2} /$ day) (time of study: 0 to 500 years) 
For the two lower values $D_{c, \text { rif }}=24 \mathrm{~mm}^{2} /$ day and $D_{c, r i f}=240 \mathrm{~mm}^{2} /$ day (respectively one hundred times and ten times smaller than the value cited by Ferretti and Bažant [21], after 500 years, almost no reaction was observed for this node. All over again, these results illustrated the significant relevance of the parameters values, for the final results.

Considerng the dimension/thickness of the wall, several parametric analysis were also performed, however for the sack of brevity there results are not presented herein, further details may be seen in Oliveira [10]. For large structures, according with the adopted numerical modeling [21], the inner part of the material supplies humidity for the external one, therefore the structure maintains elevated values of humidity for longer ages. For structures with smaller dimension, the humidity diffusion happens faster, because of the smaller contribution of those parts. In coherence with the results obtained in the parametric analyses herein, experimentally, the work presented by Oliveira et al. [11] and Oliveira [10] considered a geometry simulating axisymmetric conditions in aerial lime mortar, the results indicated that there is an effect of the specimen's size on the carbonation depth. The smaller specimens presented higher carbonation depth. Further information about the multi-physics process in aerial lime can be seen in literature [50], [51].

\section{CONCLUSIONS}

This work presented a simple algorithm to simulate the carbonation evolution using a multi-physics modelling. The modelling was able to reproduce the results of Ferretti and Bažant [21], Since this work was the only publication about multi-physical simulation of aerial lime mortars, it was adopted as reference.

The sensitivity analyses were done with the presented 1D model, principally focused on the effect of carbon dioxide diffusivity and the consequence of the thickness on the studied wall. After the initial study, the results achieved demonstrated that the initial $\mathrm{CO}_{2}$ diffusivity is one of the parameters that mostly influences the carbonation profile. This conclusion indicated the relevance of an appropriate estimation of the mentioned parameter. Herein, a range from one hundred times higher and smaller the value adopted by Ferretti and Bažant [21] was considered, consequently different results for carbonation were obtained. After 50 years, the carbonation front was $\sim 5 \mathrm{~cm}$, for the smallest value adopted $\left(D_{c, r i f}=24 \mathrm{~mm}^{2} /\right.$ day); while for the highest diffusivity value, $D_{c, r i f}=240000 \mathrm{~mm}^{2} /$ day, the wall presented $\sim 80 \mathrm{~cm}$ carbonated. Similar conclusions were obtained for other ages. This work is part of a larger project undergoing at Federal University of Minas Gerais and University of Minho.

\section{ACKNOWLEDGEMENTS}

This research was Funding provided by the "Science without Frontiers" program supported by Brazilian National Council of Technological and Scientific Development (CNPq). University of Minho and Federal University of Minas Gerais are also gratefully acknowledged.

\section{CITATIONS}

[1] B. Lagerblad, "Carbon Dioxide Uptake During Concrete Life, Sate of the Art. Sweden, Denmark: Nordic Innovation Centre, 2006.

[2] B. Bary and A. Sellier, "Coupled moisture-carbon dioxide-calcium transfer model for carbonation of concrete," Cement Concr. Res., vol. 34, no. 10, pp. 1859-1872, 2004, http://dx.doi.org/10.1016/j.cemconres.2004.01.025.

[3] G. Villain, M. Thiery, and G. Platret, "Measurement methods of carbonation profiles in concrete: thermogravimetry, chemical analysis and gammadensimetry," Cement Concr. Res., vol. 37, no. 8, pp. 1182-1192, 2007, http://dx.doi.org/10.1016/j.cemconres.2007.04.015.

[4] O. Burkan Isgor and A. G. Razaqpur, "Finite element modeling of coupled heat transfer, moisture transport and carbonation processes in concrete structures," Cement Concr. Compos., vol. 26, no. 1, pp. 57-73, 2004, http://dx.doi.org/10.1016/S0958-9465(02)00125-7.

[5] C.-F. Chang and J.-W. Chen, "The experimental investigation of concrete carbonation depth," Cement Concr. Res., vol. 36, no. 9, pp. 1760-1767, 2006, http://dx.doi.org/10.1016/j.cemconres.2004.07.025.

[6] G. Cultrone, E. Sebastián, and M. O. Huertas, "Forced and natural carbonation of lime-based mortars with and without additives: mineralogical and textural changes," Cement Concr. Res., vol. 35, no. 12, pp. 2278-2289, 2005, http://dx.doi.org/10.1016/j.cemconres.2004.12.012.

[7] C. Ewertson and P. E. Petersson, "The influence of curing conditions on the permeability and durability of concrete: results from a field exposure test," Cement Concr. Res., vol. 23, no. 3, pp. 683-692, 1993, http://dx.doi.org/10.1016/0008-8846(93)90019-6.

[8] F. P. Glasser, J. Marchand, and E. Samson, "Durability of concrete - Degradation phenomena involving detrimental chemical reactions," Cement Concr. Res., vol. 38, no. 2, pp. 226-246, 2008, http://dx.doi.org/10.1016/j.cemconres.2007.09.015.

[9] A. V. Saetta and R. V. Vitaliani, "Experimental investigation and numerical modeling of carbonation process in reinforced concrete structures: Part I: theoretical formulation," Cement Concr. Res., vol. 34, no. 4, pp. 571-579, 2004, http://dx.doi.org/10.1016/j.cemconres.2003.09.009. 
[10] M. A. Oliveira, "A multi-physics approach applied to masonry structures with non-hydraulic lime mortars," Ph.D. dissertation, Dep. Eng. Civ. Univ. Minho, Guimarães, Portugal, 2016.

[11] M. A. Oliveira et al., "Experimental analysis of the carbonation and humidity diffusion processes in aerial lime mortar," Constr. Build. Mater., vol. 148, pp. 38-48, 2017, http://dx.doi.org/10.1016/j.conbuildmat.2017.04.120.

[12] W. Ashraf, "Carbonation of cement-based materials: challenges and opportunities," Constr. Build. Mater., vol. 120, pp. 558-570, 2016, http://dx.doi.org/10.1016/j.conbuildmat.2016.05.080.

[13] R. L. Berger, J. F. Young, and K. Leung, "Acceleration of hydration of calcium silicates by carbon dioxide treatment," Nat. Phys. Sci., vol. 240, no. 97, pp. 16-18, 1972, http://dx.doi.org/10.1038/physci240016a0.

[14] L. Shen et al., "Factory-level measurements on $\mathrm{CO}_{2}$ emission factors of cement production in China," Renew. Sustain. Energy Rev., vol. 34, pp. 337-349, 2014, http://dx.doi.org/10.1016/j.rser.2014.03.025.

[15] E. Possan et al., "CO 2 uptake potential due to concrete carbonation: a case study," Case Stud. Constr. Mater., vol. 6, pp. 147-161, 2017, https://doi.org/10.1016/j.cscm.2017.01.007.

[16] R. M. H. Lawrence, “A study of carbonation in non-hydraulic lime mortars,” Ph.D. dissertation, Dep. Architec. Civ. Eng., Univ. Bath, Bath, 2006.

[17] R. Langenbach, "Rescuing the baby from the bathwater: traditional masonry as earthquake-resistant construction," in Proc. 8th Int. Masonry Conf. 2010, Dresden, Germany, 2010.

[18] A. Moropoulou, A. Bakolas, P. Moundoulas, E. Aggelakopoulou, and S. Anagnostopoulou, "Strength development and lime reaction in mortars for repairing historic masonries," Cement Concr. Compos., vol. 27, no. 2, pp. 289-294, 2005, http://dx.doi.org/10.1016/j.cemconcomp.2004.02.017.

[19] L. Binda, A. Saisi, and C. Tiraboschi, "Investigation procedures for the diagnosis of historic masonries," Constr. Build. Mater., vol. 14, no. 4, pp. 199-233, 2000, http://dx.doi.org/10.1016/S0950-0618(00)00018-0.

[20] J. Lanas and J. I. Alvarez, "Masonry repair lime-based mortars: factors affecting the mechanical behavior," Cement Concr. Res., vol. 33, no. 11, pp. 1867-1876, 2003, http://dx.doi.org/10.1016/S0008-8846(03)00210-2.

[21] D. Ferretti and Z. P. Bažant, "Stability of ancient masonry towers: moisture diffusion, carbonation and size effect," Cement Concr. Res., vol. 36, no. 7, pp. 1379-1388, 2006, http://dx.doi.org/10.1016/j.cemconres.2006.03.013.

[22] D. Ferretti and Z. P. Bažant, "Stability of ancient masonry towers: Stress redistribution due to drying, carbonation, and creep," Cement Concr. Res., vol. 36, no. 7, pp. 1389-1398, 2006, http://dx.doi.org/10.1016/j.cemconres.2006.03.014.

[23] A. Arizzi and G. Cultrone, "The influence of aggregate texture, morphology and grading on the carbonation of non-hydraulic (aerial) lime-based mortars," Q. J. Eng. Geol. Hydrogeol., vol. 46, no. 4, pp. 507-520, 2013, http://dx.doi.org/10.1144/qjegh2012-017.

[24] P. Faria, F. Henriques, and V. Rato, "Comparative evaluation of aerial lime mortars for architectural conservation," J. Cult. Herit., vol. 9, no. 3, pp. 338-346, 2008, http://dx.doi.org/10.1016/j.culher.2008.03.003.

[25] J. Lanas et al., "Mechanical behavior of masonry repair mortars: aerial and hydraulic lime-based mixtures," in Proc. 10th Int. Congr. Deterior. Conserv. Stone, Stockholm, 2004.

[26] Y. Lo and H. M. Lee, "Curing effects on carbonation of concrete using a phenolphthalein indicator and Fourier-transform infrared spectroscopy," Build. Environ., vol. 37, no. 5, pp. 507-514, 2002, http://dx.doi.org/10.1016/S0360-1323(01)00052-X.

[27] V. G. Papadakis et al., "Fundamental modeling and experimental investigation of concrete carbonation," Mater. J., vol. 88, pp. 363373, 1991.

[28] A. V. Saetta, B. A. Schrefler, and R. V. Vitaliani, "The carbonation of concrete and the mechanism of moisture, heat and carbon dioxide flow through porous materials," Cement Concr. Res., vol. 23, no. 4, pp. 761-772, 1993, http://dx.doi.org/10.1016/00088846(93)90030-D.

[29] T. Ishida and C. Li, "Coupling of mass transport and equilibrium in micro-pore structure of concrete," J. Adv. Concr. Technol., vol. 6, no. 2, pp. 303-316, 2008, http://dx.doi.org/10.3151/jact.6.303.

[30] T. Ishida and K. Maekawa, "Modeling of $\mathrm{pH}$ profile in pore water based on mass transport and chemical equilibrium theory," Concr. Libr. JSCE, vol. 37, pp. 151-166, 2001.

[31] T. Ishida, K. Maekawa, and M. Soltani, "Theoretically identified strong coupling of carbonation rate and thermodynamic moisture states in micropores of concrete," J. Adv. Concr. Technol., vol. 2, no. 2, pp. 213-222, 2004, http://dx.doi.org/10.3151/jact.2.213.

[32] W. Puatatsananon and V. Saouma, "Nonlinear coupling of carbonation and chloride diffusion in concrete," J. Mater. Civ. Eng., vol. 17, no. 3, pp. 264-275, 2005, http://dx.doi.org/10.1061/(ASCE)0899-1561(2005)17:3(264).

[33] A. Steffens, D. Dinkler, and H. Ahrens, "Modeling carbonation for corrosion risk prediction of concrete structures," Cement Concr. Res., vol. 32, no. 6, pp. 935-941, 2002, http://dx.doi.org/10.1016/S0008-8846(02)00728-7.

[34] D. Bunte and F. Rostasy, "Ingenieurmodell zur Vorhersage der Dauerhaftigkeit gegen karbonatisierungsinduzierte Korrosion der Bewehrung," in Proc. 12th Int. Conf. Build. Mater., Weimar, Germany, 1994.

[35] A. V. Saetta et al., "Analysis of chloride diffusion into partially saturated concrete," Mater. J., vol. 90, pp. 441-451, 1993. 
[36] S. A. Meier, M. A. Peter, A. Muntean, and M. Böhm, "Dynamics of the internal reaction layer arising during carbonation of concrete," Chem. Eng. Sci., vol. 62, no. 4, pp. 1125-1137, 2007, http://dx.doi.org/10.1016/j.ces.2006.11.014.

[37] M. A. Peter, A. Muntean, S. A. Meier, and M. Böhm, "Competition of several carbonation reactions in concrete: A parametric study," Cement Concr. Res., vol. 38, no. 12, pp. 1385-1393, 2008, http://dx.doi.org/10.1016/j.cemconres.2008.09.003.

[38] A. V. Saetta, "Durabilità delle strutture di calcestruzzo armato e analisi dei fenomeni di diffusione dei materiali multifase," Ph.D. dissertation, Univ. Padova, Padova, 1992.

[39] A. V. Saetta, B. A. Schrefler, and R. V. Vitaliani, "2-D model for carbonation and moisture/heat flow in porous materials," Cement Concr. Res., vol. 25, no. 8, pp. 1703-1712, 1995, http://dx.doi.org/10.1016/0008-8846(95)00166-2.

[40] A. V. Saetta and R. V. Vitaliani, "Experimental investigation and numerical modeling of carbonation process in reinforced concrete structures: Part II. Practical applications," Cement Concr. Res., vol. 35, no. 5, pp. 958-967, 2005, http://dx.doi.org/10.1016/j.cemconres.2004.06.023.

[41] M. Azenha, "Numerical simulation of the structural behaviour of concrete since its early ages," Ph.D. dissertation, Sch. Eng., Univ. Porto, Porto, 2009.

[42] P. Atkins, Shriver and Atkins' Inorganic Chemistry, 5th ed. New York: OUP Oxford, 2010.

[43] N. R. Buenfeld and N. M. Hassanein, "Life prediction of concrete structures using neural networks," in Proc. ICE - Struct. Build, 1998, pp. 38-48.

[44] F. P. Incropera et al., Introduction to Heat Transfer, 5th ed. Hoboken: John Wiley \& Sons, 2007.

[45] M. A. Oliveira, M. Azenha, and P. B. Lourenço, "Simulation of humidity fields in concrete: experimental validation and parameter estimation," J. Adv. Concr. Technol., vol. 13, no. 4, pp. 214-229, 2015., http://dx.doi.org/10.3151/jact.13.214.

[46] J. Stewart, Calculus, 6th ed. Boston: Cengage Learn., 2007.

[47] L. Binda et al., "The collapse of the Civic Tower of Pavia: a survey of the materials and structure," Mason. Int., vol. 6, pp. 11-20, 1992.

[48] S. Pavía et al., "An assessment of lime mortars for masonry repair," in Proc. Concr. Res. Irel. Colloq., Dublin, 2006, pp. 101-108.

[49] A. Anzani, E. Garavaglia, and L. Binda, "Long-term damage of historic masonry: a probabilistic model," Constr. Build. Mater., vol. 23, no. 2, pp. 713-724, 2009, http://dx.doi.org/10.1016/j.conbuildmat.2008.02.010.

[50] M. Oliveira, M. Azenha, P. B. Lourenço, A. Meneghini, and E. Guimarães, "Estudo experimental do fluxo de umidade em argamassas de cal aérea," Rev. Materia, vol. 24, no. 4, e12520, 2019, http://dx.doi.org/10.1590/s1517-707620190004.0845.

[51] R. Veiga, "Air lime mortars: What else do we need to know to apply them in conservation and rehabilitation interventions? A review," Constr. Build. Mater., vol. 157, pp. 132-140, 2017, http://dx.doi.org/10.1016/j.conbuildmat.2017.09.080.

Author contributions: MA: conceptualization, funding acquisition, supervision, writing; PBL: conceptualization, formal analysis, methodology, writing.

Editors: Paulo Cesar Correia Gomes, José Luiz Antunes de Oliveira e Sousa, Guilherme Aris Parsekian. 